'Institute of Maternal and Child Research, University of Chile, Santiago, 8330091, Chile

2Pediatrics Division, School of Medicine, Pontificia Universidad Catolica de Chile Santiago, 8330074, Chile. ${ }^{3}$ Institute of Nutrition and Food Technology, University of Chile, Santiago, 7810851, Chile.

${ }^{4}$ Dutch Growth Research Foundation, $3001 \mathrm{~KB}$

Rotterdam, The Netherlands ${ }^{5}$ Department of Pediatrics,

Subdivision of Endocrinology, Erasmus University Medical

Center, Sophia Children's Hospital, $3000 C B$

Rotterdam, The Netherlands.

Correspondence to V.M

vmerica@med.uchile.c

doi:10.1038/nrendo.2016.127

Published online 19 Aug 2016

\title{
Long-term metabolic risk among children born premature or small for gestational age
}

\author{
Veronica Mericq ${ }^{1}$, Alejandro Martinez-Aguayo ${ }^{2}$, Ricardo Uauy ${ }^{2,3}$, German Iñiguez', \\ Manouk Van der Steen ${ }^{4,5}$ and Anita Hokken-Koelega $a^{4,5}$
}

Abstract | Accumulating evidence suggests that both the intrauterine environment and growth during early life can influence the development of chronic noncommunicable diseases, such as type 2 diabetes mellitus and cardiovascular disease, in adulthood. Here, we review the available human data supporting increased metabolic risk among children born premature or small for gestational age; the adrenal and pubertal modifications that contribute to this risk; metabolic changes that occur during adolescence and early adulthood; and approaches to potentially modify or decrease risk of metabolic disease. The risks associated with delivery at term or preterm are compared for each period of life. Knowledge of these associations is fundamental for the paediatric community to develop preventive strategies early during postnatal life.

The onset of chronic noncommunicable diseases, such as type 2 diabetes mellitus and cardiovascular disease, has traditionally been attributed to the presence of specific risk factors in mid-adult life. However, data derived from developed countries and, to a lesser extent, from developing countries have provided a wealth of evidence to suggest that, in some cases, increased risk might already be present during fetal development, early infancy and childhood. The initial reports were based on retrospective data from individuals aged older than 60 years for whom birth size was not always fully described in terms of SD and gestational age $(G A)^{1}$. Nevertheless, research conducted in this area during the past 2 decades has markedly improved our understanding of the association between early life and long-term health.

The current working hypothesis to explain the development of long-term risk among individuals with a low birthweight - used as a surrogate measure for prenatal growth restriction - was based on an adaptive response to in utero malnutrition interacting with patterns of growth during infancy and childhood. A decrease in insulin sensitivity is considered the hallmark of this 'programming' hypothesis ${ }^{2,3}$. Nevertheless, fetal growth is also modulated by changes in maternal glucose concentrations and blood pressure during pregnancy, which are in part determined by the mother's genotype. Such maternal changes contribute to an increased risk of disease in the offspring through both genetic inheritance and intrauterine programming ${ }^{4,5}$, lending support for a 'fetal insulin' hypothesis. These two mechanisms might also explain interindividual differences in metabolic risk owing to heterogeneity in the pathogenesis of births characterized as small for their GA (SGA).

The placenta is the key third player known to modulate fetal growth. This organ is critical for mediating appropriate developmental responses and for integration of the environmental signals that enable healthy growth in utero. For example, the mRNA and protein expression levels of insulin-like growth factor 1 (IGF1) and its receptor IGF1R are increased in the placentas of mothers who delivered SGA offspring ${ }^{6,7}$. In addition, increased activation of placental IGF1R, AKT and mTOR (key signalling molecules downstream of the IGF1 receptor) has been reported among preterm individuals born $\mathrm{SGA}^{8}$. These results suggest that a compensatory mechanism in response to fetal growth restriction might induce other changes to increase the amounts of amino acids and glucose transferred from the placenta to the fetus. Hence, both the fetus and the placenta seem to respond to environmental signals favouring fetal growth through epigenetic mechanisms (interactions between genes and the environment that alter gene expression and produce different phenotypes) ${ }^{9,10}$. Low birthweight is associated with cardiovascular and metabolic diseases in adulthood ${ }^{11,12}$. The available evidence supporting the concept of critical developmental periods that define risk for some noncommunicable diseases is briefly summarized in (FIG. 1).

Here, we review the available human data supporting increased metabolic risk among children born premature or SGA; the adrenal and pubertal modifications that 


\section{Key points}

- The intrauterine environment and growth during early life can influence the development of chronic noncommunicable diseases, such as type 2 diabetes mellitus and cardiovascular disease

- Children born premature or small for gestational age are at increased risk of these metabolic diseases, especially those who gain weight rapidly during infancy

- Timing of adrenarche, frequency of clinical manifestations (axilarche/pubarche) and onset of puberty seem to be altered, although studies have produced conflicting results

- This cluster of adrenal-gonadal-metabolic abnormalities has not been confirmed among boys

- Conditions affecting intrauterine growth and development predispose individuals to early onset of hypertension, chronic kidney disease and endothelial, vascular and metabolic abnormalities

- Preventive strategies should start early during postnatal life to avoid rapid weight gain

\section{Preterm birth}

Preterm birth occurs before 37 weeks of gestation and is defined by the estimated GA as a proxy of maturity. Three subgroups are distinguished by the WHO: preterm ( $<37$ weeks), very preterm or very low birthweight $(<32$ weeks $)$ and extremely preterm $(<28 \text { weeks })^{13}$. These definitions are very important when interpreting data from populations classified as preterm, low birthweight or SGA.

\section{Growth charts}

Ideally, up-to-date neonatal charts are required to assess growth within the target population for which the chart is built and to which it will apply. Two types of growth charts are currently available.

Standard growth chart A standard growth chart represents ideal healthy intrauterine growth for the selected population and offers higher sensitivity than a referential growth chart for risk of morbidity and mortality ${ }^{18-20}$. However, the growth norm for a severely preterm neonate might be difficult to draw if this type of chart is used, making its clinical utility questionable. IUGR is more frequent among preterm infants than term infants ${ }^{21}$; consequently, this condition correlates with premature birth and so affected individuals are expected to be classified as SGA on the basis of such standards.

Referential growth chart A referential chart describes a population with no reference to the health status of the individuals included ${ }^{20}$. However, such charts potentially exhibit low sensitivity for detecting a neonate with growth anomalies. A set of exclusion criteria can be defined to avoid the methodological weaknesses associated with clinical use of a reference chart. Nevertheless, no agreement exists as to which diseases should be taken into consideration, especially given that some diseases, such as internal malformations and some genetic syndromes, might go unnoticed at birth. From a practical standpoint, use of a reference can be safely adopted in clinical practice when the chart is based on a population with a low prevalence of risk factors (such as the populations of developed countries $)^{20}$. In addition, conditional and customized references are available in some countries; these references are used primarily by obstetricians who wish to make adjustments for variables such as ethnicity, fetal sex and maternal anthropometry ${ }^{19}$. A systematic review of the evidence suggested that customized charts might help to improve the detection of IUGR, especially among less affluent countries or ethnic groups characterized by short stature ${ }^{19}$.

\section{Metabolic risk and SGA}

\section{Metabolic features in early life}

Compared with their AGA counterparts, SGA neonates display increased insulin sensitivity, which is associated with elevated levels of IGFBP1, free fatty acids and $\beta$-hydroxybutyrate ${ }^{22}$. This state gradually shifts to insulin resistance over the first 3 years of life, a change that is related to the rate of weight gain occurring during 


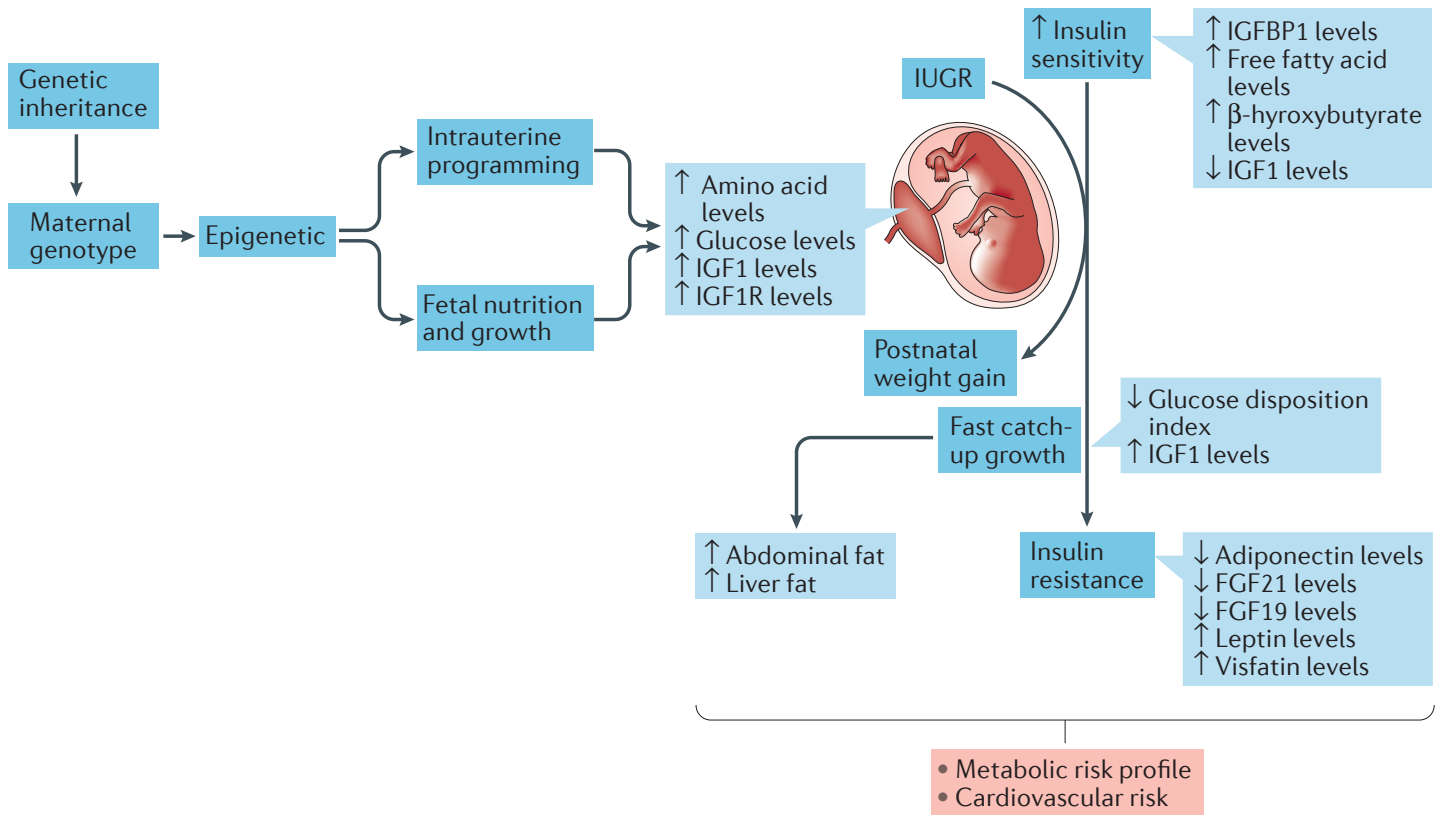

Figure 1 | The fetal insulin hypothesis and risk of metabolic disease. The fetal insulin hypothesis could explain the long-term risk of metabolic disease observed among individuals with a low birthweight through both genetic mechanisms and intrauterine programming. The placenta is critical for integration of environmental signals, thereby enabling healthy fetal growth and development. This process is mediated in part by increased expression of insulin-like growth factor 1 (IGF1) and its receptor (IGF1R), suggesting a compensatory mechanism in response to fetal growth restriction that could induce other changes to promote influx of amino acids and glucose from the maternal blood supply via the placenta to the fetus. After birth, a period of increased insulin sensitivity occurs, which gradually decreases relative to postnatal weight gain (catch-up growth). These changes could, in turn, be associated with adverse body composition and increased cardiovascular risk. FGF19, fibroblast growth factor 19; FGF21, fibroblast growth factor 21; IGFBP1, IGF binding protein 1; IUGR, intrauterine growth restriction.

this time frame. At 3 years of age, children born SGA exhibit lower insulin sensitivity (represented by a higher HOMA index) than children born AGA; however, the first phase of the insulin response does not differ between these two populations ${ }^{2}$. Consequently, the glucose disposition index (the ratio between the first phase insulin response and the HOMA index) is lower among those born SGA than those born AGA, suggesting an incomplete $\beta$-cell compensation of the decreased insulin sensitivity ${ }^{2,22}$.

The observed changes in insulin sensitivity are accompanied by changes in IGF1 levels. The serum levels of IGF1 are lower at delivery, but higher at age 3 years, among those born SGA versus $\mathrm{AGA}^{23}$. Interestingly, within the population of infants born SGA, the concentration of IGF1 at 1 year is positively associated with length gain from birth and insulin secretion. By contrast, IGF1 levels are related to BMI and insulin resistance at age 3 years (when catch-up growth is complete). Increased levels of IGF1 among SGA infants might indicate the presence of resistance to IGF1 or the ability of insulin to increase IGF1 synthesis when nutrition is improved relative to those infants born $\mathrm{AGA}^{23}$. During infancy, changes in metabolism and body composition are characterized by increases in abdominal ${ }^{24}$ and hepatic $\mathrm{fat}^{25}$; lowered levels of adiponectin ${ }^{26}$, FGF2 $1^{27}$, FGF $19^{27}$ and leptin ${ }^{28}$; and expression of vascular biomarkers of atherogenesis ${ }^{27,29,30}$.

\section{Catch-up growth in early life}

The tempo of first-year weight gain (fast or slow) seems to influence metabolic risk. A study of young adults born AGA or SGA found that those who gained weight most rapidly (fast catch-up) during the first 3 months of life had the worst cardiovascular and metabolic risk profile ${ }^{3}$. The cost of fast postnatal recovery on long-term metabolic risk was assessed among infants born SGA but with no evidence of IUGR ('innate SGA') ${ }^{31}$. After birth, individuals with innate SGA remained lighter and shorter than those born AGA but displayed a similar percentage of body fat (assessed by skin-fold measurements). No differences were observed in metabolic and hormonal parameters up to 2 years of age. These results emphasize that measures of intrauterine and postnatal early infant growth should be assessed to correctly identify children at metabolic risk.

The catch-up phenomenon might be driven by increased appetite. Indeed, SGA infants who achieve large weight gains do not exhibit marked reductions in circulating levels of ghrelin after an intravenous glucose load, which suggests that sustained orexigenic drive could contribute to postnatal catch-up growth ${ }^{32}$. Other mechanisms participating in increased appetite or reduced energy expenditure among these children could be part of an adaptation phenomena to ensure weight recovery ${ }^{33,34}$. Weight gain during refeeding of semistarved rats is differentially partitioned to fat mass at the expense of lean mass when compared with weight-matched control 
rats fed ad libitum $^{35}$. This phenomenon is possibly related to a redistribution of glucose use towards adipose-tissue gain during catch-up growth ${ }^{35,36}$. Indeed, important epigenetic modifications in metabolic signalling pathways are already present in early postnatal life ${ }^{37}$. A prenatally impaired metabolism and morphology of adipose-tissue development facilitates rapid catch-up growth.

An abnormal ratio of white adipose tissue to brown adipose tissue might also be present. One study tested the hypothesis that biological memory of the prenatal state among growth-restricted individuals is reflected in epigenetic alterations in stem-cell populations ${ }^{38}$. This study identified candidate genes and selected acyl-coenzyme A synthetase 1 (ACSL1; encoded by ACSL1) for further analysis. This enzyme is crucial for lipid synthesis, as well as for the activation, transport and degradation of fatty acids. The overexpression of ACSL1 in mature adipocytes isolated from SGA infants was associated with increased lipid loading and increased insulin sensitivity, confirming previous observations that SGA infants are insulin sensitive at birth ${ }^{22}$ but become insulin resistant later in life ${ }^{2}$. Upregulation of ACSL1 expression among individuals born SGA could, therefore, function as a double-edged sword in that it promotes rapid catch-up growth but also increases the release of esterified fatty acids, eventually leading to insulin resistance. Alternatively, ACSL1-driven triglyceride biosynthesis could be speculated to quicken the onset of obesity and so enable subsequent development of metabolic disorders. High caloric intake accelerates the ACSL1-dependent pathway, increasing both the expression of this enzyme and acting on downstream genes $^{38}$. Thus, elevated ACSL1 levels and consumption of a high-calorie diet could act synergistically to induce obesity and related comorbidities among individuals born SGA.

A case-control study performed in China showed that term and preterm SGA neonates displayed profiles suggestive of lower insulin sensitivity and less favourable lipid metabolism at 3 days of life when compared with those born $\mathrm{AGA}^{39}$. This discrepancy might be attributed to the selection criteria, with a high proportion of SGA infants delivered by women with hypertension; a high proportion of caesarian births, which are associated with neonatal hyperinsulinism ${ }^{40}$; inclusion of individuals with innate $\mathrm{SGA}^{41}$; differences in the mothers' parity, prepregnancy BMI and weight gain during pregnancy ${ }^{42}$; or the use of formula rather than breastfeeding.

Approximately $10-15 \%$ of all individuals born SGA do not complete postnatal catch-up growth $(>-2 \mathrm{SD}$ scores) and remain of short stature during childhood ${ }^{43,44}$. Most cases are not associated with growth hormone (GH) deficiency but rather exhibit varying degrees of resistance along the GH-IGF-insulin signalling axis ${ }^{45-47}$. Identification of a specific molecular basis is, therefore, recommended among all SGA infants who present with severe insulin resistance.

\section{Metabolic features in childhood}

Insulin sensitivity is determined mainly by BMI and the birthweight SD score among prepubertal children ${ }^{48,49}$. In some studies, differences in insulin sensitivity and secretion only emerge after using the euglycaemichyperinsulinaemic clamp, the gold standard for assessing this parameter ${ }^{49}$. Impaired insulin sensitivity was detected in a group of SGA children with short stature $(n=15)$ compared with similarly short but normal birthweight children $(n=12)$; however, no difference was found in glucose effectiveness, a measure of the ability of glucose to enhance its own disposal and suppress its production $^{50}$. This study used the modified frequently sampled intravenous glucose tolerance test analysed by the Bergman model, which is an accurate, but timeconsuming and invasive tool. However, the SGA children enrolled in the study ${ }^{50}$ belonged to the less frequent group with "non-catch-up" growth ${ }^{43}$. As described above, we cannot rule out that within this group of SGA children, some might harbour IGF1R mutations that cause both insulin resistance and IUGR.

\section{Metabolic risk and preterm birth}

Advances in neonatal care have enabled an increased proportion of premature neonates with very low birthweight and extremely low birthweight to survive. As these advances have been implemented only over the past 3 decades, it might be too soon to examine the long-term consequences of this type of prematurity.

\section{Metabolic features in early life}

Premature neonates are at risk of abnormalities in glucose homeostasis during the first week of postnatal life, with most requiring parenteral glucose administration ${ }^{51}$. The development of hypoglycaemia is multifactorial and involves decreased glycogen stores $^{52}$, limited gluconeogenesis $^{53}$, limited ketogenesis ${ }^{54}$ and other conditions that increase energy requirements (for example, perinatal asphyxia, sepsis and hypothermia) ${ }^{51}$. Hypoglycaemia can also occur among preterm infants as a consequence of transient hyperinsulinism. The molecular basis of transient hyperinsulinism is unknown but patients respond well to the potassium-channel activator diazoxide $e^{50}$.

Hyperglycaemia is also a frequent finding among individuals born preterm (up to $68 \%$ versus just $5 \%$ for individuals born at term); this complication is inversely related to the degree of immaturity ${ }^{55}$. Many conditions are associated with neonatal hyperglycaemia, including stress, treatment with drugs such as steroids or methylxanthines, and administration of glucose at high rates. Other frequent contributing factors include elevated plasma insulin levels ${ }^{56}$; increased levels of pro-insulin (which is 10-fold less active than mature insulin) owing to defective $\beta$-cell processing of this molecule; and partial resistance to insulin action ${ }^{57}$, which might reflect a post-receptor defect. Finally, insulin-sensitive tissues, such as adipose tissue, are less abundant among preterm neonates than term neonates ${ }^{54}$. These conditions limit the interpretation of research results and call for caution in assessing insulin sensitivity early after preterm birth.

A study of the effect of glucocorticoid therapy on very low birthweight preterm infants (SGA or AGA) found no differences in basal insulin sensitivity; however, steroids decreased insulin sensitivity only in the SGA group ${ }^{58}$. Another study used a milk-tolerance test 
during the first 2 months after delivery and showed that insulin sensitivity was related to both weight SD scores and weight gain at the time of testing ${ }^{59}$.

\section{Metabolic features in childhood}

A Chilean cohort of premature very low birthweight children studied at age 5.7 years demonstrated that those born SGA had increased fasting levels of insulin ${ }^{48}$. This link was independent of GA and other indicators of postnatal stress, including early requirements for ventilator and nutritional support. In addition, fasting and first-phase insulin secretion were related to instant postnatal growth velocity (a measurement of catch-up growth independent of size at birth), in accordance with previous observations in term neonates ${ }^{48}$. Adiposity was the main determinant of insulin sensitivity and secretion at age 5.7 years ${ }^{48}$. A prospective follow-up study of 385 preterm children aged 9-12 years found that blood glucose levels assessed after an oral glucose tolerance test were negatively correlated with birthweight SD scores independent of the length of gestation ${ }^{60}$. Postnatal catch-up growth and childhood weight gain were the most important factors influencing the insulin concentration.

A discordant finding was reported in a study conducted in New Zealand ${ }^{61}$. Children born preterm displayed similar insulin sensitivity to children born SGA at term, regardless of their previous growth in utero (birthweight SD score); furthermore, both groups exhibited lower insulin sensitivity values than did the group of children who were born AGA at term. The interaction between size at birth and early postnatal growth on determining insulin sensitivity is clearly relevant ${ }^{62-64}$, with the results of different studies possibly reflecting differences in neonatal care and/or nutrition. However, caution should be exercised in extending these observations to other preterm populations as SGA individuals born preterm who remain of short stature might not represent the most common growth patterns among SGA infants born at term.

\section{Metabolic features in adulthood}

Adults delivered preterm with very low birthweight display lower insulin sensitivity than their peers born at term with a similar BMI ${ }^{65}$. In young adulthood (mean age, 25 years), this lowered insulin sensitivity remains compensated by higher insulin secretion than observed in those born at term ${ }^{65}$.

\section{Catch-up growth after preterm birth}

Rapid growth also imposes a metabolic cost among preterm infants ${ }^{66,67}$. Body composition reveals altered adipose-tissue partitioning, with an increased proportion of trunk adiposity associated with accelerated postnatal weight gain ${ }^{68-71}$. Early postnatal growth among preterm infants has been negatively correlated with cord blood levels of leptin ${ }^{72}$. Total-body adipose mass and trunk adipose mass both correlate negatively with birthweight SD score but positively with weight gain during the first 3 months of life ${ }^{73}$. Furthermore, a reciprocal association of percentage adipose mass with resting energy expenditure at age 6 years is observed ${ }^{73}$. By contrast, the rate of weight gain after 6 months of life is associated with increased rates of lipid oxidation and increased lean mass at 6 years of age $\mathrm{e}^{73}$.

Finally, very low birthweight children who are delivered preterm have an increased risk of neurological impairment. Poor postnatal growth is an independent risk factor for adverse neurodevelopmental outcomes and different brain maturation patterns among such individuals $\mathrm{s}^{74,75}$

\section{Adrenal and pubertal modifications Adrenarche}

Several studies have investigated the timing of adrenarche; the frequency of clinical manifestations (axillary hair and/ or pubarche); and the onset and progression of puberty among children born $\mathrm{SGA}^{76-78}$. Nonetheless, the results are difficult to compare owing to variations in the definition of SGA used, inclusion criteria, methodology, ethnic and genetic background, and follow-up periods.

Adrenarche is defined as puberty of the adrenal gland, whereas pubarche indicates the appearance of pubic hair, which might be accompanied by axillary hair growth. This process is considered premature if it occurs before age 8 years in girls and 9 years in boys ${ }^{77}$. Premature adrenarche has gained much attention over the past 2 decades as it is associated with the presence of insulin resistance and the metabolic syndrome. The presence of adiposity markers exacerbates premature adrenarche, increasing the risk of noncommunicable diseases in adulthood ${ }^{79-81}$. In some cohorts, being born SGA or premature is associated with an increased chance of accelerated puberty and development of polycystic ovarian syndrome ${ }^{82,83}$. Both insulin resistance and increased levels of IGF1 are associated with a hyperandrogenic adrenal and/or ovarian state ${ }^{84,85}$; these two conditions are frequently seen after catch-up growth among children born SGA. Thus, after completing catch-up growth but before starting puberty, girls born SGA develop a metabolic pattern that includes central adiposity; hyperinsulinaemia; hypoadiponectinaemia; hyperleptinaemia; dyslipidaemia; lowered levels of sex hormone-binding globulin; increased levels of dehydroepiandrosterone sulfate; and accelerated bone maturation ${ }^{76,86}$. The lowered adiponectin levels are not related to insulin resistance, which points to a defect in adipose-tissue production of metabolic factors ${ }^{87,88}$. However, these associations must be analysed with caution owing to possible ethnic differences: variations in serum dehydroepiandrosterone sulfate, IGF1 and fasting insulin levels could be explained by genetic factors (FIG. 2) (REF. 89)' (REF. 90).

\section{Pubertal development}

Children born SGA The hypothalamic-gonadal axis seems to be affected by reprogramming among children born SGA. Despite the limitations of the available studies, the majority establish that the onset of puberty begins within the normal age range, but earlier among SGA children than those born $\mathrm{AGA}^{91-94}$. In addition, faster progression of puberty, with accelerated bone maturation, an earlier peak height velocity and a lower total height gain during puberty leads to a shorter adult height and 


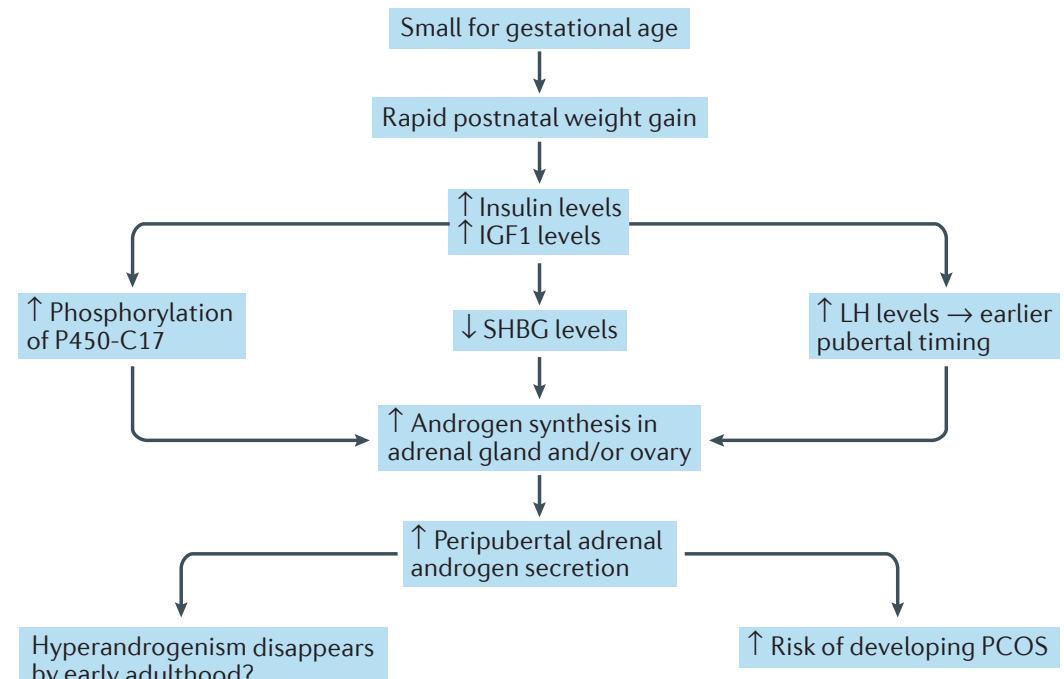

by early adulthood?

Figure 2 | The relationship between insulin resistance and the hyperandrogenic state. The hyperandrogenic state observed among some girls born small for gestational age might reflect insulin resistance, increased levels of free insulin-like growth factor 1 (IGF1), and decreased levels of sex hormone-binding globulin (SHBG). These factors are associated with increased secretory pulses of luteinizing hormone $(\mathrm{LH})$, leading to increased synthesis and secretion of androgens. An association between increased phosphorylation of the insulin receptor and steroid

17- $\alpha$-hydroxylase/17,20 lyase (also known as 17- $\alpha$-hydroxyprogesterone aldolase or $\mathrm{P} 450-\mathrm{C} 17)$ could be a common mechanism in insulin resistance and hyperandrogenism. PCOS, polycystic ovary syndrome.

an earlier age at menarche among individuals born SGA versus their AGA counterparts ${ }^{87,95-98}$. However, some prospective studies did not find any evidence that birthweight or SGA were associated with clinically important early onset of puberty among girls ${ }^{92,99}$ or boys ${ }^{93,100}$. By contrast, increased secretion of follicle-stimulating hormone (FSH) and decreased size of internal genitalia have been reported in a Spanish population of pubertal girls born SGA ${ }^{101,102}$; however, this finding was not replicated by other studies ${ }^{103}$. Interestingly, the cluster of adrenal-gonadal-metabolic abnormalities has not been confirmed among boys born SGA ${ }^{104-106}$.

Children born preterm Only limited data are available regarding pubertal development among children born preterm. A Finnish study of individuals born preterm with very low birthweight found that adults were likely to experience an early pubertal growth spurt ( $\geq 2$ years earlier than the population average $)^{107}$. Activation of the hypothalamic-pituitary-gonadal axis in infancy is increased among both preterm girls and boys when compared with term infants ${ }^{108,109}$, a finding that warrants future investigation regarding the impact on pubertal development. Indeed, longitudinal data with a long duration of follow-up is lacking among preterm children.

\section{The hypothalamic-pituitary-adrenal axis}

Chronically increased secretion of corticotropinreleasing hormone, adrenocorticotropic hormone and cortisol in utero might be partly responsible for fetal reprogramming of the hypothalamic-pituitary-adrenal axis $^{110,111}$. Placental corticotropin-releasing hormone is stimulated by cortisol in association with diminished activity of placental corticosteroid 11- $\beta$-dehydrogenase isozyme 2 (also known as 11- $\beta$-hydroxysteroid dehydrogenase type 2 ) in conditions of chronic stress, and it modulates fetal pituitary-adrenal function in highrisk pregnancies (FIG. 3) (REF. 111)' (REF. 112). Similarly, the fetus responds to adversity in early life by premature activation of the hypothalamic-pituitary-adrenal axis and premature upregulation of key regulatory genes at each level along the axis. Low birthweight is positively correlated with cortisol levels in adulthood; furthermore, cortisol levels are strongly associated with insulin resistance, elevated blood pressure and risk of the metabolic syndrome $e^{113-115}$. Conditions affecting intrauterine growth and development predispose individuals to early onset of hypertension, chronic kidney disease and endothelial, vascular and metabolic abnormalities ${ }^{116-118}$. Therefore, it is difficult to conclude whether the cardiovascular risk occurs as a consequence of preterm birth, low birthweight or other factors.

\section{Cardiovascular and adrenal consequences}

Children born SGA Experimental models and epidemiological data suggest that intrauterine events can affect vasculogenesis and endothelial function, as well as vascular-wall structure. Both endothelium-independent and endothelium-dependent vasodilation (well-recognized precursors of hypertension and atherosclerosis) might be impaired among infants with low birthweight, possibly persisting into adult life. Children born at term (birthweight $\leq 2,500 \mathrm{~g}$ ) exhibited impaired endothelial function and increased systolic blood pressure by the age of $8-13$ years ${ }^{119}$. Similar findings were reported among 315 adults with low birthweight ${ }^{120}$.

An inverse association is observed between birthweight and the levels of blood pressure, serum aldosterone and cortisol among children born at $>32$ weeks of gestation who are within the normal spectrum for birthweight, suggesting that fetal programming of the hypothalamic-pituitary-adrenal axis occurs ${ }^{121}$. This association persists after controlling for the BMI SD score and pubertal state ${ }^{121}$. In agreement with this result, another study found that both birthweight and ponderal index (defined as 'birth weight/height x 100') were positively related to the total area under the curve and bedtime cortisol levels ${ }^{122}$.

Limited information is available on mineralocorticoid activity in prenatally programmed hypertension. In an animal model of IUGR, activation of the reninangiotensin-aldosterone system is evidenced by decreased activity of plasma renin and an increased concentration of plasma aldosterone even before the onset of hypertension ${ }^{123}$.

SGA girls born at term have substantially elevated circulating levels of noradrenaline, whereas the levels of angiotensin- 2 and the activity of angiotensin-converting enzyme are increased among SGA boys born at term ${ }^{124}$. This finding supports a link between low birthweight and overactivity of the sympathetic nervous system and the renin-angiotensin-aldosterone system during later childhood. 


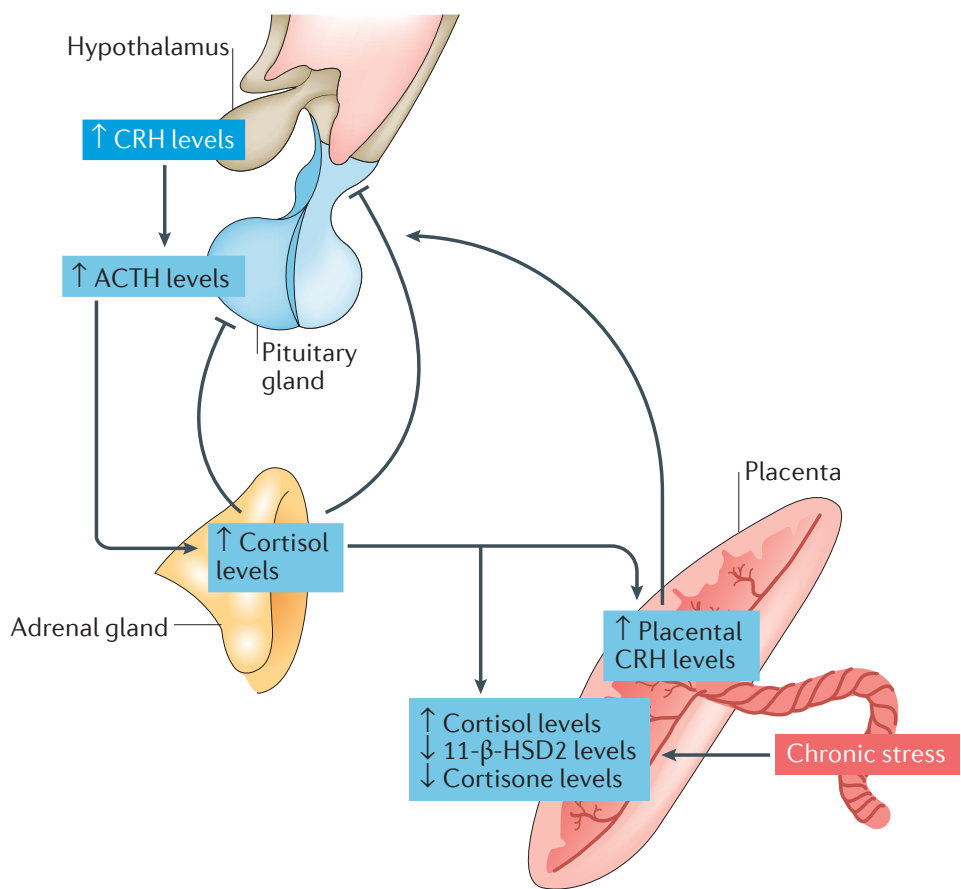

Figure 3 | Reprogramming of the hypothalamic-pituitary-adrenal axis. Chronically increased secretion of corticotropin-releasing hormone $(\mathrm{CRH})$, adrenocorticotropic hormone (ACTH) and cortisol in utero might be partly responsible for reprogramming of the hypothalamic-pituitary-adrenal axis. Placental CRH is stimulated by cortisol, in association with diminished activity of placental corticosteroid $11-\beta$-dehydrogenase isozyme 2 (also known as $11-\beta$-hydroxysteroid dehydrogenase type 2 ; $11-\beta$-HSD2), under conditions of chronic stress that modulate fetal pituitary-adrenal function among high-risk pregnancies.
These findings highlight the importance of long-term cardiovascular surveillance for this vulnerable group that should extend into adulthood ${ }^{134}$. If blood pressure among preterm individuals can be reduced by $2-3 \mathrm{mmHg}$ (that is, to the levels seen among individuals born at term), then their risk of future hypertension, stroke and ischaemic heart disease could be markedly reduced ${ }^{135}$. Preterm SGA children have higher systolic and diastolic blood pressure levels than children who are born SGA at term ${ }^{136}$. However, one study found that after excluding term SGA children, the systolic and diastolic blood pressure levels were higher among girls born preterm than girls born at term ${ }^{137}$.

Endothelial dysfunction and permanent alterations in the microcirculation might be present among children who were born preterm; these changes contribute to the process of atherosclerosis, a major determinant of cardiovascular disease $\mathrm{e}^{138,139}$. Cardiovascular risk probably reflects multiple factors. For example, preterm neonates have reduced numbers of nephrons at birth and an increased risk of developing hypertension and renal insufficiency, which in turn increases cardiovascular risk ${ }^{140}$.

Rapid postnatal weight gain is also associated with elevated blood pressure in the preterm population ${ }^{141-144}$. Among children and adolescents who had extremely low birthweight, increased blood pressure was associated with an increased speed of weight gain at an early stage after delivery during the first 3 years of life $\mathrm{e}^{141}$.

Consequently, identification of the factors and mechanisms related to elevated blood pressure among individuals born extremely preterm is important to design effective prevention and treatment strategies. These approaches will provide evidence-based recommendations for the management of elevated blood pressure among affected individuals throughout their lifespan.

\section{Consequences in adolescents and adults Individuals born at term}

Short adults born SGA have elevated systolic and diastolic blood pressure ${ }^{145}$. Carotid-intima media thickness (a measure of the extent of atherosclerosis) is similar among short SGA individuals and adults of normal stature who were born AGA but higher among SGA adults with spontaneous catch-up growth to normal weight and height $^{146}$.

Adults born SGA have a lower lean body mass than those born $\mathrm{AGA}^{147}$. The percentage of fat mass (assessed by DXA) is similar among short SGA and AGA adults but higher among SGA adults with spontaneous catch-up growth ${ }^{147,148}$. Spontaneous catch-up in weight in early infancy is positively associated with fasting insulin levels and insulin resistance as defined by HOMA in adolescence ${ }^{149}$, a finding in line with increased fasting insulin levels among short adolescents born SGA ${ }^{150-155}$. Insulin sensitivity measured by frequently sampled intravenous glucose tolerance is similar among SGA and AGA adults but lower among SGA adults with spontaneous catch-up growth ${ }^{152}$. Lipid profiles among adults born SGA are similar to those of adults born $\mathrm{AGA}^{153,155}$ 
Thus, young adults (age 18-24 years) born SGA who exhibit an early, spontaneous catch-up in weight are more likely to have an unfavourable body composition and lower insulin sensitivity than their age-matched peers who remained short ${ }^{149,156-158}$.

\section{Individuals born preterm}

Young adults (age 18-24 years) born preterm exhibit higher systolic blood pressure, resting heart rate, pulse pressure and blood-pressure variability over time than young adults born at term ${ }^{159-164}$. Increased carotidintima media thickness was found among children aged 10-14 years who were born preterm ${ }^{165}$; however, no effect of gestational age on carotid-intima media thickness was found among adolescents aged 18-24 years who were born preterm ${ }^{161}$. A discrepancy exists between increased risk factors among adolescents born preterm and little or no increase in disease in later life ${ }^{166,167}$.

Trunk fat mass is an important predictor of insulin sensitivity in adulthood; this factor tends to be higher among adults born preterm than among adults born at term ${ }^{168,169}$. Insulin sensitivity is reduced among preterm children aged $4-10$ years $^{61}$. By contrast, no association was found between prematurity and lowered insulin sensitivity in a large cohort of adults aged 18-24 years who were born preterm ${ }^{168}$. Individuals with very low birthweight display lower insulin sensitivity than their peers born at term, for which they compensate by increased insulin secretion ${ }^{65}$. This combination of low insulin sensitivity and compensatory insulin secretion might represent an early phase in the pathway leading to type 2 diabetes mellitus. Although no association between gestational age and the levels of total cholesterol, LDL cholesterol, HDL cholesterol, triglycerides and apolioprotein $\mathrm{B}$ was found ${ }^{169}$, there are some conflicting data on lipid levels among adults born preterm ${ }^{162,169}$.

\section{Box 1 | Long-term effects of growth hormone therapy in individuals born SGA}

Blood pressure

- A decline in systolic and diastolic blood pressure SD scores occurs during growth hormone (GH) treatment ${ }^{177,178}$

- At 6.5 years after $\mathrm{GH}$ treatment, systolic and diastolic blood pressure SD scores are lower among $\mathrm{GH}$-treated adults than untreated adults ${ }^{145}$

Body composition

- Adipose-tissue mass decreases and lean-body mass increases during GH treatment ${ }^{177,178,218}$

- At 6.5 years after $\mathrm{GH}$ treatment, adipose-tissue mass and lean-body mass are similar among $\mathrm{GH}$-treated and untreated adults ${ }^{147}$

Glucose metabolism

- Insulin sensitivity decreases and insulin secretion increases during $\mathrm{GH}$ treatment ${ }^{183,184,186,187}$

- At 6.5 years after $\mathrm{GH}$ treatment, insulin sensitivity and insulin secretion are similar among $\mathrm{GH}$-treated and untreated adults ${ }^{145}$

Lipid levels

- The levels of total cholesterol, LDL cholesterol and HDL cholesterol decrease during $\mathrm{GH}$ treatment ${ }^{177,178}$

- At 6.5 years after $\mathrm{GH}$ treatment, cholesterol levels are similar among $\mathrm{GH}$ treated and untreated adults ${ }^{145}$

SGA, small for gestational age
The underlying cause of increased cardiovascular risk among adults born preterm is unknown. Nevertheless, accelerated gain in weight for length SD scores during the period from preterm birth to term age, as well as during the first 3 months after term age, contributes substantially to an increased body fat percentage, waist circumference, acute insulin response and lower disposition index in early adulthood and an increased risk of nonalcoholic fatty liver disease ${ }^{61,63,170-172}$. Further research is needed to evaluate whether or not these differences will increase rates of cardiovascular disease and impaired glucose tolerance later in life. Such data will be of major importance as an increasing number of children born preterm are now reaching adulthood.

\section{Effects of GH therapy}

Administration of $\mathrm{GH}$ is an approved treatment to improve adult height among short children born SGA without spontaneous catch-up growth ${ }^{173-176}$. However, $\mathrm{GH}$ treatment causes changes in body composition and insulin resistance. Concern has, therefore, been expressed regarding the long-term consequences of $\mathrm{GH}$ treatment among children born SGA (BOX 1).

Cardiovascular features Blood pressure SD scores decrease during long-term GH therapy ( $\sim 6$ years). Furthermore, at 6.5 years after discontinuation of treatment, systolic blood pressure SD scores are substantially lower than those recorded at the start of treatment, whereas diastolic blood pressure remains similar to baseline $\mathrm{e}^{145,177,178}$. Among previously GH-treated adults born SGA, both systolic and diastolic blood pressure SD scores at 6.5 years after therapy are markedly lower than those of untreated short adults born SGA ${ }^{145}$. Carotid-intima media thickness is similar among GH-treated versus untreated children born SGA; however, this measure has not been studied among GH-treated adolescents and adults born $\mathrm{SGA}^{179}$.

Body composition Long-term treatment with GH leads to a substantial decline in total-fat mass SD score ${ }^{180-182}$. Discontinuation of $\mathrm{GH}$ is associated with marked changes in body composition 6 months after the end of treatment, including increases in percentage body fat and fat mass SD score and a decrease in lean body mass SD score $^{182}$. Among previously $\mathrm{GH}$-treated young adults (age 18-24 years) who were born SGA, body composition and fat distribution (trunk fat plus limb fat, as defined by DXA) at 6.5 years after treatment are similar to those of untreated short adults born SGA ${ }^{147}$. These findings suggest that catch-up growth induced by GH exerts no unfavourable effects on either fat mass or fat distribution.

Insulin sensitivity Short children born SGA exhibit reduced insulin sensitivity before receiving GH treatment ${ }^{125}$. Such therapy causes a further decline in insulin sensitivity and a compensatory increase in insulin secretion $^{145,183-188}$. Therefore, concerns have been expressed regarding the long-term effects of $\mathrm{GH}$ treatment on risk factors for type 2 diabetes mellitus. One study found that the lowered insulin sensitivity induced by GH among 
adolescents born SGA was reversible after concluding long-term ( $\sim 6$ years) of treatment ${ }^{182}$. At 6 months after stopping $\mathrm{GH}$, insulin sensitivity became similar to that of AGA control individuals ${ }^{182}$. At 6.5 years after discontinuation of treatment, insulin sensitivity and secretion were similar among GH-treated and untreated short adults aged 22 years who were born SGA ${ }^{145}$.

Lipid levels Treatment with GH was associated with a reduction in total cholesterol, HDL cholesterol and LDL cholesterol levels, which remained lower than those recorded at baseline until 6.5 years after the end of therapy $^{145,177}$. Cholesterol levels at 6.5 years after GH treatment were similar to levels among untreated short adults born SGA ${ }^{145}$.

Puberty GH-treated children born SGA who start puberty at a height of $<140 \mathrm{~cm}$ can benefit from additional treatment with a gonadotropin-releasing hormone agonist to delay puberty for 2 years ${ }^{189}$. Body composition, blood pressure and lipid levels at adult height were similar among adolescents treated with a combination of GH and a gonadotropin-releasing hormone agonist and adolescents treated with GH only ${ }^{189,190}$. Additional GnRH agonist treatment for 2 years can, therefore, be considered among SGA children who start puberty with a height of $<140 \mathrm{~cm}$.

Thus, treatment with $\mathrm{GH}$ provides favourable effects on metabolic and cardiovascular determinants, with the data of previously GH-treated adults similar to that of their untreated peers after discontinuation of therapy. Nonetheless, how metabolic health develops with age among these individuals remains to be elucidated.

\section{Can the risks be changed?}

A proposal published in 2013 highlighted the need to focus on the crucial period from conception to a child's second birthday as the window of opportunity during which good nutrition and healthy growth could offer benefits that last throughout the life course ${ }^{191}$.

\section{Insulin-sensitizing therapy}

Early accumulation of visceral adiposity following postnatal catch-up growth among children born SGA leads to insulin resistance ${ }^{24}$. Therefore, insulin-sensitizing therapy might help to prevent this metabolic change.

The efficacy of early (at age 7.9 years) treatment with metformin among girls displaying precocious pubarche has been tested. One study found both less adipose tissue and delayed onset of puberty after 4 years of metformin use; however, linear growth was maintained ${ }^{192}$. In addition, metformin therapy was associated with lowered levels of insulin, leptin and IGF1 but increased levels of sex hormone-binding globulin and IGFBP1, as well as a less atherogenic lipid profile and leaner body composition ${ }^{192}$. These findings emphasize the role of insulin as a key co-determinant of pubertal pace and height growth among girls born SGA. The observed improvements in body composition (lowered total and abdominal adiposity), fasting insulin levels, lipid profile and adipokine profile (a lowered leptin-to-adiponectin ratio) persisted 12 months after discontinuation of treatment ${ }^{193}$.
Furthermore, prepubertal intervention with metformin reduced central adiposity and improved insulin sensitivity among a small group of nonobese children born SGA who had spontaneously attained catch-up growth ${ }^{194}$.

\section{Nutritional modification}

Fetal programming can be explained by epigenetic changes, which are defined as stable, heritable alterations in genes that are mediated via covalent modifications of DNA and core histones without any concomitant changes in the DNA sequence.

Given that DNA methylation is a key modulator of epigenetic changes, it might be possible to limit such effects through nutritional or other interventions. For example, transgenerational exposure of agouti mice to an ad libitum diet caused obesity associated with the metabolic syndrome in their offspring ${ }^{195}$. Furthermore, obesity can be prevented in other mouse models by dietary supplementation with folate ${ }^{196}$, vitamin $B_{12}$ (REF. 196), choline ${ }^{196}, \omega-3$ fatty acids ${ }^{197}$ (specifically docosahexaenoic acid) and other nutrients that affect methylation of nuclear DNA. Although research is still limited, nutrition is expected to have a key role in developmental plasticity and programming of various physiological conditions.

Breastfeeding versus formula A meta-analysis found that breastfeeding for 1 month correlated with a $4 \%$ decrease in obesity risk ${ }^{198}$. Another advantage of breastfeeding is a lowered level of the proinflammatory advanced glycation endproducts found in thermally processed food that correlates with serum levels of these products and the development of insulin resistance ${ }^{199}$. Furthermore, a French study demonstrated that dietary protein was the only macronutrient associated with weight gain at age 2 years $^{200}$.

In a multicenter European study, healthy infants were randomly assigned to receive cow-milk-based infant formula and follow-on formula of either low-protein content $\left(12.5 \mathrm{~kg} / \mathrm{m}^{3}\right.$ and $16.0 \mathrm{~kg} / \mathrm{m}^{3}$, respectively) or high-protein content $\left(20.5 \mathrm{~kg} / \mathrm{m}^{3}\right.$ and $33.0 \mathrm{~kg} / \mathrm{m}^{3}$, respectively) for the first year after delivery ${ }^{201}$. A group of breastfed infants was included for comparison; the average protein content of the breast milk was estimated to be $12.0 \mathrm{~kg} / \mathrm{m}^{3}$. Infants who received the high-protein formula were heavier and had a higher BMI at 1 and 2 years of age than the infants fed low-protein formula or breast milk. When characterizing the metabolic-endocrine response, those fed the high-protein formula received similar total energy intake to the infants receiving low-protein formula. Furthermore, increased levels of essential amino acids, branched-chain amino acids, IGF1 and insulin release were detected after 6 months ${ }^{202}$. Levels of degradation products of branched-chain amino acids (the short-chain acylcarnitines C3, C4 and C5) were also markedly elevated in the high-protein group, leading to saturation of the degradation pathway and subsequent inhibition of the initial step of $\beta$ oxidation, thereby increasing weight gain and adipositity ${ }^{203}$.

Two randomized, controlled trials of children born SGA with a low birthweight ( $<10$ th percentile) showed that the use of enriched formula (containing 28-43\% 
more protein and $6-12 \%$ more energy than the formula used in the term group) led to a higher fat mass at 5 years than was observed in the control group (range, $18-38 \%)^{204}$. Trials comparing different nutritional interventions among premature infants with very low birthweight have shown discordant effects on postnatal growth $^{205-207}$. Higher 32-33 split proinsulin (the predominant form of proinsulin, which accounts for the disproportionate hyperproinsulinaemia), was detected among adolescents aged 13-16 years born preterm who had participated in a randomized intervention of a nutrient-enriched formula compared with those who received a control formula ${ }^{208}$.

A large prospective study conducted in Chile found that premature infants who received preterm formulas for $\geq 6$ months had lower trunk-fat mass by the first and second year and lower total-fat mass (as measured by DXA) by the second year when compared with individuals who received these formulas solely while in the neonatal intensive care unit ${ }^{209}$. These changes in body composition were accompanied by decreased levels of fasting insulin in the first 2 years. Long-term follow up of this cohort is still required; however, these results are promising and suggest that preterm infants fed formulas enriched with docosahexaenoic acid could potentially have a healthier metabolic profile than those fed term formulas, which lack such enrichment.

$\boldsymbol{\omega}$-3 fatty acids Docosahexaenoic acid is an important component of neural and retinal membranes that rapidly accumulates in the brain during gestation and the postnatal period ${ }^{210}$. Positive associations have been found between maternal intake of fish, seafood and $\omega-3$ fatty acids during pregnancy and/or lactation and the subsequent visual and cognitive development of their offspring ${ }^{211}$. In addition to growth and neurodevelopmental effects, docosahexaenoic acid induces gene expression that might benefit metabolism ${ }^{212,213}$.
The long-chain polyunsaturated fatty acids arachadonic acid and eicosapentaenoic acid are important biomediators that can affect growth and body composition through diverse mechanisms ${ }^{214,215}$. Rats fed diets enriched in fish oil (rich in docosahexaenoic acid) ingested more food calories after 4 weeks than rats fed diets enriched in carbohydrates ${ }^{216}$. However, the animals fed fish oil weighed less and had a lower percentage of body fat (measured by DXA) and liver triglyceride content than the control animals. Fish oil blunted the normal postprandial decline in the mRNA expression levels of factors involved in the degradation of fatty acids (PPARa, CPT1 and ACO) and blunted the normal postprandial rise in the mRNA expression levels of factors involved in triglyceride synthesis (SREBP1c, FAS, SCD1). Therefore, the direct postprandial effect of fish oil ingestion was to decrease the storage of hepatic triglycerides, and to decrease total body weight, total body fat and hepatic steatosis ${ }^{216}$. However, the current evidence does not conclusively support or refute that supplementation with $\omega$-3 long-chain polyunsaturated fatty acids benefits body composition or cognitive and visual development. This lack of conclusive support probably reflects methodological limitations in the trials conducted to date ${ }^{217}$.

\section{Conclusions}

Concrete evidence supports an effect of the intrauterine environment and early infant growth on child and adolescent growth and in the development of noncommunicable diseases. Knowledge of these associations is fundamental for the paediatric community to develop preventive strategies early in postnatal life. The challenge going forward is to prevent intrauterine insults and, if present, to develop early lifestyle interventions and/or pharmacotherapy to reverse the pathophysiological changes and preserve $\beta$-cell function to prevent the development of metabolic conditions.
1. Barker, D. J. et al. Type 2 (non-insulin-dependent) diabetes mellitus, hypertension and hyperlipidaemia (syndrome X): relation to reduced fetal growth. Diabetologia 36, 62-67 (1993).

2. Mericq, V. et al. Longitudinal changes in insulin sensitivity and secretion from birth to age three years in small- and appropriate-for-gestational-age children. Diabetologia 48, 2609-2614 (2005).

3. Leunissen, R. W., Kerkhof, G. F., Stijnen, T. \& Hokken-Koelega, A. Timing and tempo of first-year rapid growth in relation to cardiovascular and metabolic risk profile in early adulthood. JAMA 301 2234-2242 (2009).

4. Hattersley, A. T. et al. Mutations in the glucokinase gene of the fetus result in reduced birth weight. Nat. Genet. 19, 268-270 (1998).

5. Freathy, R. M. et al. Variants in ADCY5 and near $C C N L 1$ are associated with fetal growth and birth weight. Nat. Genet. 42, 430-435 (2010).

6. Iniguez, G. et al. Expression and protein content of IGF-I and IGF-I receptor in placentas from small, adequate and large for gestational age newborns. Horm. Res. Paediatr. 73, 320-327 (2010).

7. Iniguez, G. et al. Acid-labile subunit (ALS) gene expression and protein content in human placentas: differences according to birth weight. J. Clin. Endocrinol. Metab. 96, 187-191 (2011).

8. Iniguez, G. et al. IGF-IR signal transduction protein content and its activation by IGF-I in human placentas: relationship with gestational age and birth weight.
PLOS ONE 9, http://dx.doi.org/10.1371/journal. pone.0102252 (2014).

9. Bourque, D. K., Avila, L., Penaherrera, M., von Dadelszen, P. \& Robinson, W. P. Decreased placental methylation at the H19/IGF2 imprinting control region is associated with normotensive intrauterine growth restriction but not preeclampsia. Placenta 31, 197-202 (2010).

10. Maccani, M. A., Padbury, J. F. \& Marsit, C. J. miR-16 and miR-21 expression in the placenta is associated with fetal growth. PLOS ONE 6, http://dx.doi. org/10.1371/journal.pone.0021210 (2011).

11. Barker, D. J., Winter, P. D., Osmond, C., Margetts, B. \& Simmonds, S. J. Weight in infancy and death from ischaemic heart disease. Lancet 2, 577-580 (1989)

12. Barker, D. J. The fetal and infant origins of adult disease. BMJ 301, 1111 (1990)

13. World Health Organisation. ICD-10 Version 2016 Certain conditions originating in the perinatal period. Ch. XV1. P05-P08 [online] http://apps.who.int/ classifications/icd 10/browse/2016/en\#!/P05.9 (WHO, 2016)

14. Sherry, B., Mei, Z., Grummer-Strawn, L. $\delta$ Dietz, W. H. Evaluation of and recommendations for growth references for very low birth weight $(<$ or $=1500$ grams) infants in the United States. Pediatrics 111, 750-758 (2003).

15. World Health Organisation. Intrauterine growth retardation in newborn children. [online] http://www. who.int/ceh/indicators/iugrnewborn.pdf (WHO, 2015).
16. Boguszewski, M. C. et al. Latin American consensus: children born small for gestational age. BMC Pediatr. 11 (2011).

17. Clayton, P. E. et al. Management of the child born small for gestational age through to adulthood: a consensus statement of the International Societies of Pediatric Endocrinology and the Growth Hormone Research Society. J. Clin. Endocrinol. Metab. 92, 804-810 (2007)

18. Rao, S. C., Tompkins, J. \& World Health Organization. Growth curves for preterm infants. Early Hum. Dev. 83, 643-651 (2007)

19. Gelbaya, T. A. \& Nardo, L. G. Customised fetal growth chart: a systematic review. J. Obstet. Gynaecol. 25 445-450 (2005)

20. Bertino, E., Milani, S., Fabris, C. \& De Curtis, M. Neonatal anthropometric charts: what they are, what they are not. Arch. Dis. Child Fetal Neonatal Ed. 92, F7-F10 (2007).

21. Ott, W. J. Intrauterine growth retardation and preterm delivery. Am. J. Obstet. Gynecol. 168, 1710-1715; discussion 1715-1717 (1993).

22. Bazaes, R. A. et al. Glucose and lipid metabolism in small for gestational age infants at 48 hours of age. Pediatrics 111, 804-809 (2003).

23. Iniguez, G. et al. Longitudinal changes in insulin-like growth factor-I, insulin sensitivity, and secretion from birth to age three years in small-for-gestational-age children. J. Clin. Endocrinol. Metab. 91, 4645-4649 (2006). 
24. Ibanez, L., Ong, K., Dunger, D. B. \& de Zegher, F. Early development of adiposity and insulin resistance after catch-up weight gain in small-for-gestational-age children. J. Clin. Endocrinol. Metab. 91, 2153-2158 (2006).

25. Faienza, M. F. et al. Nonalcoholic fatty liver disease in prepubertal children born small for gestational age: influence of rapid weight catch-up growth. Horm. Res. Paediatr. 79, 103-109 (2013)

26. Mericq, V. et al. Serum fibroblast growth factor 21 levels are inversely associated with growth rates in infancy. Horm. Res. Paediatr. 82, 324-331 (2014).

27. Sanchez-Infantes, D. et al. Circulating FGF19 and FGF21 surge in early infancy from infra- to supra-adult concentrations. Int. J. Obes. (Lond.) 39, 742-746 (2015).

28. Soto, N. et al. Insulin sensitivity and secretion are related to catch-up growth in small-for-gestational-age infants at age 1 year: results from a prospective cohort. J. Clin. Endocrinol. Metab. 88, 3645-3650 (2003).

29. Sebastiani, G. et al. The sequence of prenatal growth restraint and post-natal catch-up growth leads to a thicker intima-media and more pre-peritoneal and hepatic fat by age 3-6 years. Pediatr. Obes. 11, 251-257 (2016)

30. Tanaka, Y. et al. Lower birth weight and visceral fat accumulation are related to hyperinsulinemia and insulin resistance in obese Japanese children. Hypertens. Res. 28, 529-536 (2005).

31. Milovanovic, I. et al. Innate small babies are metabolically healthy children. J. Clin. Endocrinol. Metab. 97, 4407-4413 (2012).

32. Iniguez, G. et al. Fasting and post-glucose ghrelin levels in SGA infants: relationships with size and weight gain at one year of age. J. Clin. Endocrinol. Metab. 87 5830-5833 (2002).

33. Vickers, M. H., Breier, B. H., McCarthy, D. \& Gluckman, P. D. Sedentary behavior during postnatal life is determined by the prenatal environment and exacerbated by postnatal hypercaloric nutrition. Am. J. Physiol. Regul. Integr. Comp. Physiol. 285, R271-R273 (2003).

34. Ikenasio-Thorpe, B. A., Breier, B. H., Vickers, M. H. \& Fraser, M. Prenatal influences on susceptibility to diet-induced obesity are mediated by altered neuroendocrine gene expression. J. Endocrinol. 193, 31-37 (2007)

35. Cettour-Rose, P. et al. Redistribution of glucose from skeletal muscle to adipose tissue during catch-up fat: a link between catch-up growth and later metabolic syndrome. Diabetes 54, 751-756 (2005).

36. Crescenzo, R. et al. A role for suppressed thermogenesis favoring catch-up fat in the pathophysiology of catch-up growth. Diabetes $\mathbf{5 2}$ 1090-1097 (2003)

37. Schultz, N. S. et al. Impaired leptin gene expression and release in cultured preadipocytes isolated from individuals born with low birth weight. Diabetes 63 111-121 (2014)

38. Joseph, R. et al. ACSL1 Is associated with fetal programming of insulin sensitivity and cellular lipid content. Mol. Endocrinol. 29, 909-920 (2015).

39. Wang, X., Cui, Y., Tong, X., Ye, H. \& Li, S. Glucose and lipid metabolism in small-for-gestational-age infants at 72 hours of age. J. Clin. Endocrinol. Metab. 92 681-684 (2007)

40. Hoe, F. M. et al. Clinical features and insulin regulation in infants with a syndrome of prolonged neonatal hyperinsulinism. J. Pediatr. 148, 207-212 (2006).

41. Beltrand, J. et al. Catch-up growth following fetal growth restriction promotes rapid restoration of fat mass but without metabolic consequences at one year of age. PLOS ONE 4, http://dx.doi.org/10.1371 journal.pone.0005343 (2009).

42. Linares, J. et al. The effects of pre-pregnancy BMI and maternal factors on the timing of adiposity rebound in offspring. Obes. (Silver Spring) 24, 1313-1319 (2016).

43. Hokken-Koelega, A. C. et al. Children born small for gestational age: do they catch up? Pediatr. Res. 38, 267-271 (1995)

44. Albertsson-Wikland, K., Boguszewski, M. \& Karlberg, J. Children born small-for-gestational age: postnatal growth and hormonal status. Horm. Res. 49 (Suppl. 2), 7-13 (1998).

45. Ranke, M. B. et al. IGF-I and IGF binding protein-3 levels during initial $\mathrm{GH}$ dosage step-up are indicators of $\mathrm{GH}$ sensitivity in $\mathrm{GH}$-deficient children and short children born small for gestational age. Horm. Res. 64 68-76 (2005).
46. Edghill, E. L. et al. Insulin mutation screening in 1,044 patients with diabetes: mutations in the INS gene are a common cause of neonatal diabetes but a rare cause of diabetes diagnosed in childhood or adulthood. Diabetes 57, 1034-1042 (2008).

47. Begemann, M. et al. Paternally inherited IGF2 mutation and growth restriction. N. Engl. J. Med. 373, 349-356 (2015).

48. Bazaes, R. A. et al. Determinants of insulin sensitivity and secretion in very-low-birth-weight children. J. Clin Endocrinol Metab 89, 1267-1272 (2004).

49. Veening, M. A., Van Weissenbruch, M. M. \& Delemarre-Van De Waal, H. A. Glucose tolerance, insulin sensitivity, and insulin secretion in children born small for gestational age. J. Clin. Endocrinol. Metab. 87, 4657-4661 (2002).

50. Hofman, P. L. et al. Insulin resistance in short children with intrauterine growth retardation. J. Clin. Endocrinol. Metab. 82, 402-406 (1997).

51. Lyall, H., Burchell, A., Howie, P. W., Ogston, S. \& Hume, R. Early detection of metabolic abnormalities in preterm infants impaired by disorders of blood glucose concentrations. Clin. Chem. 40, 526-530 (1994).

52. Shelley, H. J., Bassett, J. M. \& Milner, R. D. Control of carbohydrate metabolism in the fetus and newborn. Br. Med. Bull. 31, 37-43 (1975).

53. Hume, R. $\&$ Burchell, A. Abnormal expression of glucose-6-phosphatase in preterm infants. Arch. Dis. Child. 68, 202-204 (1993)

54. Hawdon, J. M., Ward Platt, M. P. \& Aynsley-Green, A. Patterns of metabolic adaptation for preterm and term infants in the first neonatal week. Arch. Dis. Child. 67, 357-365 (1992).

55. Hey, E. Hyperglycaemia and the very preterm baby Semin. Fetal Neonatal Med. 10, 377-387 (2005).

56. Hawdon, J. M., Aynsley-Green, A., Alberti, K. G. \& Ward Platt, M. P. The role of pancreatic insulin secretion in neonatal glucoregulation. I. Healthy term and preterm infants. Arch. Dis. Child. 68, 274-279 (1993).

57. Farrag, H. M. et al. Persistent glucose production and greater peripheral sensitivity to insulin in the neonate versus the adult. Am. J. Physiol. 272, E86-E93 (1997).

58. Leipala, J. A., Raivio, K. O., Sarnesto, A., Panteleon, A \& Fellman, V. Intrauterine growth restriction and postnatal steroid treatment effects on insulin sensitivity in preterm neonates. J. Pediatr. 141, 472-476 (2002).

59. Gray, I. P., Cooper, P. A., Cory, B. J., Toman, M. \& Crowther $\mathrm{N}$. J. The intrauterine environment is a strong determinant of glucose tolerance during the neonatal period, even in prematurity. J. Clin. Endocrinol. Metab. 87, 4252-4256 (2002).

60. Fewtrell, M. S. et al. Effects of size at birth, gestational age and early growth in preterm infants on glucose and insulin concentrations at 9-12 years. Diabetologia 43 714-717 (2000).

61. Hofman, P. L. et al. Premature birth and later insulin resistance. N. Engl. J. Med 351, 2179-2186 (2004).

62. Bavdekar, A. et al. Insulin resistance syndrome in 8-year-old Indian children: small at birth, big at 8 years, or both? Diabetes 48, 2422-2429 (1999).

63. Finken, M. J. et al. Preterm birth and later insulin resistance: effects of birth weight and postnatal growth in a population based longitudinal study from birth into adult life. Diabetologia 49, 478-485 (2006).

64. Ong, K. K. et al. Insulin sensitivity and secretion in normal children related to size at birth, postnatal growth, and plasma insulin-like growth factor-I levels. Diabetologia 47 , 1064-1070 (2004).

65. Kajantie, E. et al. Insulin sensitivity and secretory response in adults born preterm: the Helsinki Study of Very Low Birth Weight Adults. J. Clin. Endocrinol. Metab. 100, 244-250 (2015).

66. Lucas, A et al. Randomized trial of nutrient-enriched formula versus standard formula for postdischarge preterm infants. Pediatrics 108, 703-711 (2001).

67. Regan, F. M., Cutfield, W. S., Jefferies, C., Robinson, E. \& Hofman, P. L. The impact of early nutrition in premature infants on later childhood insulin sensitivity and growth. Pediatrics 118, 1943-1949 (2006).

68. Gale, C. R., Martyn, C. N., Kellingray, S., Eastell, R. \& Cooper, C. Intrauterine programming of adult body composition. J. Clin. Endocrinol. Metab. 86, 267-272 (2001)

69. Uthaya, S. et al. Altered adiposity after extremely preterm birth. Pediatr. Res. 57, 211-215 (2005).

70. Tappy, L. $\&$ D’Alessio, D. Obesity and insulin resistance: is it due to body fat, energy balance, or gut factors? Curr. Opin. Clin. Nutr. Metab. Care 9, 455-457 (2006).
71. Cooke, R. J. et al. Body composition of preterm infants during infancy. Arch. Dis. Child. Fetal Neonatal Ed. 80 F188-F191 (1999)

72. Fonseca, V. M., Sichieri, R., Moreira, M. E. \& Moura, A. S. Early postnatal growth in preterm infants and cord blood leptin. J. Perinatol. 24, 751-756 (2004).

73. Sepulveda, C. et al. Differences in body composition and resting energy expenditure in childhood in preterm children born with very low birth weight. Horm. Res. Paediatr. 79, 347-355 (2013).

74. Latal-Hajnal, B., von Siebenthal, K., Kovari, H. Bucher, H. U. \& Largo, R. H. Postnatal growth in VLBW infants: significant association with neurodevelopmental outcome. J. Pediatr. 143, 163-170 (2003).

75. Okuma, C. et al. Microstructural brain and multivoxel spectroscopy in very low birth weight infants related to insulin-like growth factor concentration and early growth. Horm. Res. Paediatr. 79, 197-207 (2013).

76. Ghirri, P. et al. Adrenarche, pubertal development, age at menarche and final height of full-term, born small for gestational age (SGA) girls. Gynecol. Endocrinol. 15, 91-97 (2001).

77. Ibanez, L., Dimartino-Nardi, J., Potau, N. \& Saenger, P. Premature adrenarche - normal variant or forerunne of adult disease? Endocr. Rev. 21, 671-696 (2000).

78. Ibanez, L., Potau, N., Marcos, M. V. \& de Zegher, F. Exaggerated adrenarche and hyperinsulinism in adolescent girls born small for gestational age. J. Clin. Endocrinol. Metab. 84, 4739-4741 (1999).

79. Oppenheimer, E., Linder, B. \& DiMartino-Nardi, J. Decreased insulin sensitivity in prepubertal girls with premature adrenarche and acanthosis nigricans. J. Clin. Endocrinol. Metab. 80, 614-618 (1995).

80. Voutilainen, R. \& Jaaskelainen, J. Premature adrenarche: etiology, clinical findings, and consequences. J. Steroid Biochem. Mol. Biol. 145 226-236 (2015)

81. Denburg, M. R. et al. Insulin sensitivity and the insulinlike growth factor system in prepubertal boys with premature adrenarche. J. Clin. Endocrinol. Metab. 87 5604-5609 (2002)

82. Ibanez, L., Potau, N., Francois, I. \& de Zegher, F. Precocious pubarche, hyperinsulinism, and ovarian hyperandrogenism in girls: relation to reduced fetal growth. J. Clin. Endocrinol. Metab. 83, 3558-3562 (1998).

83. Ibanez, L. et al. Polycystic ovaries after precocious pubarche: relation to prenatal growth. Hum. Reprod. 22, 395-400 (2007)

84. Ibanez, L. et al. Growth hormone, insulin-like growth factor-I axis, and insulin secretion in hyperandrogenic adolescents. Fertil. Steril. 64, 1113-1119 (1995).

85. Guercio, G., Rivarola, M. A., Chaler, E., Maceiras, M. \& Belgorosky, A. Relationship between the growth hormone/insulin-like growth factor-I axis, insulin sensitivity, and adrenal androgens in normal prepubertal and pubertal girls. J. Clin. Endocrinol. Metab. 88, 1389-1393 (2003)

86. Ibanez, L., Lopez-Bermejo, A., Diaz, M. \& de Zegher, F. Catch-up growth in girls born small for gestational age precedes childhood progression to high adiposity Fertil. Steril. 96, 220-223 (2011).

87. Jaquet, D., Deghmoun, S., Chevenne, D. Czernichow, P. \& Levy-Marchal, C. Low serum adiponectin levels in subjects born small for gestational age: impact on insulin sensitivity. Int. J. Obes. (Lond.) 30, 83-87 (2006).

88. Verkauskiene, R., Petraitiene, I. \& Albertsson Wikland, K. Puberty in children born small fo gestational age. Horm. Res. Paediatr. 80, 69-77 (2013).

89. Estourgie-van Burk, G. F., Bartels, M. \& Boomsma, D. I. A twin-sibling study on early growth and hormone levels in adolescents. Behav. Genet 45 283-293 (2015)

90. Oron, T. et al. Interrelationship of extent of precocious adrenarche in appropriate for gestational age girls with clinical outcome. J. Pediatr. 160, 308-313 (2012).

91. Albertsson-Wikland, K. \& Karlberg, J. Natural growth in children born small for gestational age with and without catch-up growth. Acta Paediatr. Suppl. 399 64-70 (1994)

92. Karlberg, J., Kwan, C. W., Gelander, L. \& Albertsson-Wikland, K. Pubertal growth assessment. Horm. Res. 60, 27-35 (2003).

93. Persson, I. et al. Influence of perinatal factors on the onset of puberty in boys and girls: implications for interpretation of link with risk of long term diseases. Am. J. Epidemiol. 150, 747-755 (1999). 
94. Lazar, L., Pollak, U., Kalter-Leibovici, O., Pertzelan, A. \& Phillip, M. Pubertal course of persistently short children born small for gestational age (SGA) compared with idiopathic short children born appropriate for gestational age (AGA). Eur. J. Endocrinol. 149, 425-432 (2003)

95. Sloboda, D. M., Hart, R., Doherty, D. A., Pennell, C. E. $\&$ Hickey, M. Age at menarche: Influences of prenatal and postnatal growth. J. Clin. Endocrinol. Metab. 92 46-50 (2007)

96. Chaudhari, S., Otiv, M., Hoge, M., Pandit, A. $\&$ Mote, A. Growth and sexual maturation of low birth weight infants at early adolescence. Indian Pediatr. 45, 191-198 (2008)

97. Ibanez, L., Jimenez, R. \& de Zegher, F. Early pubertymenarche after precocious pubarche: relation to prenatal growth. Pediatrics 117, 117-121 (2006).

98. Labarta, J. I. et al. Growth and growth hormone treatment in short stature children born small for gestational age. Pediatr. Endocrinol. Rev. 6 (Suppl. 3), 350-357 (2009).

99. Hernandez, M. I. et al. Accelerated early pubertal progression, ovarian morphology, and ovarian function in prospectively followed low birth weight (LBW) girls. J. Pediatr. Endocrinol. Metab. 26, 223-230 (2013).

100. Hui, L. L., Leung, G. M., Wong, M. Y., Lam, T. H. \& Schooling, C. M. Small for gestational age and age at puberty: evidence from Hong Kong's "Children of 1997" birth cohort. Am. J. Epidemiol. 176, 785-793 (2012).

101. Ibanez, L., Potau, N. \& de Zegher, F. Ovarian hyporesponsiveness to follicle stimulating hormone in adolescent girls born small for gestational age. J. Clin. Endocrinol. Metab. 85, 2624-2626 (2000)

102. Ibanez, L., Potau, N., Enriquez, G. \& de Zegher, F. Reduced uterine and ovarian size in adolescent girls born small for gestational age. Pediatr. Res. 47 , 575-577 (2000)

103. Hernandez, M. I. et al. Comparison of clinical, ultrasonographic, and biochemical differences at the beginning of puberty in healthy girls born either small for gestational age or appropriate for gestational age: preliminary results. J. Clin. Endocrinol. Metab. 91, 3377-3381 (2006).

104. Potau, N., Ibanez, L., Rique, S., Sanchez-Ufarte, C. \& de Zegher, F. Pronounced adrenarche and precocious pubarche in boys. Horm. Res. 51, 238-241 (1999).

105. Boonstra, V. H., Weber, R. F., de Jong, F. H. \& Hokken-Koelega, A. C. Testis function in prepubertal boys and young men born small for gestational age. Horm. Res. 70, 357-363 (2008).

106. Jensen, R. B. et al. Pituitary-gonadal function in adolescent males born appropriate or small for gestational age with or without intrauterine growth restriction. J. Clin. Endocrinol. Metab. 92 1353-1357 (2007).

107. Wehkalampi, K. et al. Advanced pubertal growth spurt in subjects born preterm: the Helsinki study of very low birth weight adults. J. Clin. Endocrinol. Metab. 96 525-533 (2011)

108. Kuiri-Hanninen, T. et al. Postnatal developmental changes in the pituitary-ovarian axis in preterm and term infant girls. J. Clin. Endocrinol. Metab. 96, 3432-3439 (2011)

109. Kuiri-Hanninen, T. et al. Increased activity of the hypothalamic-pituitary-testicular axis in infancy results in increased androgen action in premature boys. J. Clin. Endocrinol. Metab. 96 98-105 (2011).

110. Barker, D. J. et al. Fetal nutrition and cardiovascula disease in adult life Lancet 341,938-941 (1993).

111. Goland, R. S. et al. Elevated levels of umbilical cord plasma corticotropin-releasing hormone in growthretarded fetuses. J. Clin. Endocrinol. Metab. 77, 1174-1179 (1993)

112. Moisiadis, V. G. \& Matthews, S. G. Glucocorticoids and fetal programming part 2: Mechanisms. Nat. Rev. Endocrinol. 10, 403-411 (2014)

113. Phillips, D. I. et al. Elevated plasma cortisol concentrations: a link between low birth weight and the insulin resistance syndrome? J. Clin. Endocrinol. Metab. 83, 757-760 (1998)

114. Cottrell, E. C. \& Seckl, J. R. Prenatal stress, glucocorticoids and the programming of adult disease Front. Behav. Neurosci. 3, http://dx.doi.org/10.3389/ neuro.08.019.2009 (2009)

115. Seckl, J. R. Prenatal glucocorticoids and long-term programming. Eur. J. Endocrinol. 151 (Suppl. 3), U49-U62 (2004).

116. Assadi, F. The epidemic of pediatric chronic kidney disease: the danger of skepticism. J. Nephropathol. 1 61-64 (2012).
117. Raitakari, O. T. et al. Pulse pressure in youth and carotid intima-media thickness in adulthood: the cardiovascular risk in young Finns study. Stroke 40, 1519-1521 (2009)

118. Bayrakci, U. S., Schaefer, F., Duzova, A., Yigit, S. \& Bakkaloglu, A. Abnormal circadian blood pressure regulation in children born preterm. J. Pediatr. 151 399-403 (2007)

119. Franco, M. C., Christofalo, D. M., Sawaya, A. L. Ajzen, S. A. \& Sesso, R. Effects of low birth weight in 8- to 13-year-old children: implications in endothelial function and uric acid levels. Hypertension 48, 45-50 (2006)

120. Leeson, C. P., Kattenhorn, M., Morley, R., Lucas, A \& Deanfield, J. E. Impact of low birth weight and cardiovascular risk factors on endothelial function in early adult life. Circulation 103, 1264-1268 (2001)

121. Martinez-Aguayo, A. et al. Birth weight is inversely associated with blood pressure and serum aldosterone and cortisol levels in children. Clin. Endocrinol. (Oxf.) 76, 713-718 (2012).

122. Gustafsson, P. E., Janlert, U., Theorell, T. \& Hammarstrom, A. Is body size at birth related to circadian salivary cortisol levels in adulthood? Results from a longitudinal cohort study. BMC Public Health 10, http://dx.doi.org/10.1186/1471-2458-10-346 (2010).

123. Vehaskari, V. M., Aviles, D. H. \& Manning, J. Prenatal programming of adult hypertension in the rat. Kidney Int. 59, 238-245 (2001).

124. Franco, M. C. et al. Circulating renin-angiotensin system and catecholamines in childhood: is there a role for birthweight? Clin. Sci. (Lond.) 114, 375-380 (2008).

125. Arends, N. J. et al. Reduced insulin sensitivity and the presence of cardiovascular risk factors in short prepubertal children born small for gestational age (SGA). Clin. Endocrinol. (Oxf.) 62, 44-50 (2005).

126. Martinez-Aguayo, A. et al. Comparison of leptin levels, body composition and insulin sensitivity and secretion by OGTT in healthy, early pubertal girls born at either appropriate- or small-for-gestational age. Clin. Endocrinol. (Oxf.) 67, 526-532 (2007).

127. Miras, M. et al. Serum levels of adiponectin and leptin in children born small for gestational age: relation to insulin sensitivity parameters. J. Pediatr. Endocrinol. Metab. 23, 463-471 (2010).

128. Rocchini, A. P. Obesity hypertension, salt sensitivity and insulin resistance. Nutr. Metab. Cardiovasc. Dis. 10, 287-294 (2000).

129. Cho, W. K. \& Suh, B. K. Catch-up growth and catch-up fat in children born small for gestational age. Korean J. Pediatr. 59, 1-7 (2016).

130. Shah, A. B., Hashmi, S. S., Sahulee, R., Pannu, H. \& Gupta-Malhotra, M. Characteristics of systemic hypertension in preterm children. J. Clin. Hypertens. (Greenwich) 17, 364-370 (2015).

131. Kwinta, P. et al. From a regional cohort of extremely low birth weight infants: cardiac function at the age of 7 years. Neonatology 103, 287-292 (2013).

132. Ohkubo, T. et al. Relation between nocturnal decline in blood pressure and mortality. The Ohasama Study. Am. J. Hypertens. 10, 1201-1207 (1997).

133. Verdecchia, P. et al. Ambulatory blood pressure. An independent predictor of prognosis in essential hypertension. Hypertension 24, 793-801 (1994)

134. Roberts, G., Lee, K. J., Cheong, J. L. Doyle, L. W. \& Victorian Infant Collaborative Study Group. Higher ambulatory blood pressure at 18 years in adolescents born less than 28 weeks' gestation in the 1990 s compared with term controls. J. Hypertens. 32 620-626 (2014)

135. Cook, N. R., Cohen, J., Hebert, P. R., Taylor, J. O. \& Hennekens, C. H. Implications of small reductions in diastolic blood pressure for primary prevention. Arch. Intern. Med. 155, 701-709 (1995).

136. Willemsen, R. H., de Kort, S. W., van der Kaay, D. C. \& Hokken-Koelega, A. C. Independent effects of prematurity on metabolic and cardiovascular risk factors in short small-for-gestational-age children. J. Clin. Endocrinol. Metab. 93, 452-458 (2008).

137. Sipola-Leppanen, M. et al. Cardiovascular risk factors in adolescents born preterm. Pediatrics 134 e1072-e1081 (2014)

138. Kerkhof, G. F., Breukhoven, P. E., Leunissen, R. W. Willemsen, R. H. \& Hokken-Koelega, A. C. Does preterm birth influence cardiovascular risk in early adulthood? J. Pediatr. 161, 390-396.e1 (2012).

139. Lee, H., Dichtl, S., Mormanova, Z., Dalla Pozza, R. \& Genzel-Boroviczeny, O. In adolescence, extreme prematurity is associated with significant changes in the microvasculature, elevated blood pressure and increased carotid intima-media thickness. Arch. Dis. Child. 99, 907-911 (2014).

140. Abitbol, C. L. \& Rodriguez, M. M. The long-term renal and cardiovascular consequences of prematurity. Nat. Rev. Nephrol. 8, 265-274 (2012).

141. Vohr, B. R., Allan, W., Katz, K. H., Schneider, K. C. \& Ment, L. R. Early predictors of hypertension in prematurely born adolescents. Acta Paediatr. 99 1812-1818 (2010)

142. Irving, R. J., Belton, N. R., Elton, R. A. \& Walker, B. R. Adult cardiovascular risk factors in premature babies. Lancet 355, 2135-2136 (2000)

143. Bonamy, A. K. et al. Preterm birth contributes to increased vascular resistance and higher blood pressure in adolescent girls. Pediatr. Res. 58, 845-849 (2005)

144. Belfort, M. B., Martin, C. R., Smith, V. C., Gillman, M. W. \& McCormick, M. C. Infant weight gain and school-age blood pressure and cognition in former preterm infants. Pediatrics 125, e1419-e1426 (2010).

145. Van Dijk, M., Bannink, E. M., Van Pareren, Y. K. Mulder, P. G. \& Hokken-Koelega, A. C. Risk factors for diabetes mellitus type 2 and metabolic syndrome are comparable for previously growth hormone-treated young adults born small for gestational age (SCA) and untreated short SGA controls. J. Clin. Endocrinol. Metab. 92, 160-165 (2007).

146. Leunissen, R. W., Kerkhof, G. F., Stijnen, T. $\delta$ Hokken-Koelega, A. C. Effect of birth size and catch-up growth on adult blood pressure and carotid intimamedia thickness. Horm. Res. Paediatr. 77, 394-401 (2012).

147. Breukhoven, P. E., Kerkhof, G. F., Van Dijk, M. \& Hokken-Koelega, A. C. Long-term impact of $\mathrm{GH}$ treatment during childhood on body composition and fat distribution in young adults born SGA. J. Clin. Endocrinol. Metab. 96, 3710-3716 (2011).

148. Leunissen, R. W., Stijnen, T. \& Hokken-Koelega, A. C. Influence of birth size on body composition in early adulthood: the programming factors for growth and metabolism (PROGRAM)-study. Clin. Endocrinol. (Oxf.) 70, 245-251 (2009).

149. Fabricius-Bjerre, S. et al. Impact of birth weight and early infant weight gain on insulin resistance and associated cardiovascular risk factors in adolescence. PLOS ONE 6, http://dx.doi.org/10.1371/journal. pone.0020595 (2011).

150. Leger, J. et al. Reduced final height and indications for insulin resistance in 20 year olds born small for gestational age: Regional cohort study. BMJ 315, 341-347 (1997)

151. Potau, N. et al. Hyperinsulinemia in pre- and post-pubertal children born small for gestational age. Horm. Res. 56, 146-150 (2001)

152. Leunissen, R. W. et al. Fat mass accumulation during childhood determines insulin sensitivity in early adulthood. J. Clin. Endocrinol. Metab. 93, 445-451 (2008).

153. Verkauskiene, R. et al. Birth weight and long-term metabolic outcomes: does the definition of smallness matter? Horm. Res. 70, 309-315 (2008)

154. Meas, T. et al. Independent effects of weight gain and fetal programming on metabolic complications in adults born small for gestational age. Diabetologia 53, 907-913 (2010)

155. Chiavaroli, V. et al. Progression of cardio-metabolic risk factors in subjects born small and large for gestational age. PLOS ONE 9, http://dx. doi. org/10.1371/journal.pone.0104278 (2014)

156. Eriksson, J., Forsen, T., Tuomilehto, J., Osmond, C. \& Barker, D. Fetal and childhood growth and hypertension in adult life. Hypertension 36, 790-794 (2000).

157. Forsen, T. et al. The fetal and childhood growth of persons who develop type 2 diabetes. Ann. Intern. Med. 133, 176-182 (2000).

158. Eriksson, J. G., Forsen, T., Tuomilehto, J., Osmond, C. \& Barker, D. J. Early growth and coronary heart disease in later life: longitudinal study. BMJ 322, 949-953 (2001).

159. Keijzer-Veen, M. G., Dulger, A., Dekker, F. W., Nauta, J. \& van der Heijden, B. J. Very preterm birth is a risk factor for increased systolic blood pressure at a young adult age. Pediatr. Nephrol. 25, 509-516 (2010).

160. Rossi, P. et al. Respective roles of preterm birth and fetal growth restriction in blood pressure and arterial stiffness in adolescence. J. Adolesc. Health $\mathbf{4 8}$ 520-522 (2011) 
161. Kerkhof, G. F., Breukhoven, P. E., Leunissen, R. W., Willemsen, R. H. \& Hokken-Koelega, A. C. Does preterm birth influence cardiovascular risk in early adulthood? J. Pediatr. 161, 390-396.e391 (2012).

162. Sipola-Leppänen, M. et al. Cardiovascular risk factors in adolescents born preterm. Pediatrics 134 e1072-e1081 (2014)

163. Tauzin, L. et al. Increased systemic blood pressure and arterial stiffness in young adults born prematurely. J. Dev. Orig. Health Dis. 5, 448-452 (2014).

164. Sipola-Leppänen, M. et al. Cardiometabolic risk factors in young adults who were born preterm. Am. J. Epidemiol. 181, 861-873 (2015).

165. Lee, H., Dichtl, S., Mormanova, Z., Dalla Pozza, R. \& Genzel-Boroviczeny, O. In adolescence, extreme prematurity is associated with significant changes in the microvasculature, elevated blood pressure and increased carotid intima-media thickness. Arch. Dis. Child. Educ. Pract. Ed. 99, 907-911 (2014).

166. Ueda, P et al. Cerebrovascular and ischemic heart disease in young adults born preterm: A populationbased Swedish cohort study. Eur. J. Epidemiol. 29, 253-260 (2014)

167. Kajantie, E., Osmond, C. \& Eriksson, J. G. Coronary heart disease and stroke in adults born preterm - The Helsinki Birth Cohort Study. Paediatr. Perinat. Epidemiol. 29, 515-519 (2015).

168. Willemsen, R. H., Leunissen, R. W., Stijnen, T. $\delta$ Hokken-Koelega, A. C. Prematurity is not associated with reduced insulin sensitivity in adulthood. J. Clin. Endocrinol. Metab. 94, 1695-1700 (2009).

169. Breukhoven, P. E., Kerkhof, G. F., Willemsen, R. H. \& Hokken-Koelega, A. C. Fat mass and lipid profile in young adults born preterm. J. Clin. Endocrinol. Metab. 97, 1294-1302 (2012).

170. Hovi, P. et al. Glucose regulation in young adults with very low birth weight. N. Engl. J. Med. 356, 2053-2063 (2007).

171. Kerkhof, G. F., Willemsen, R. H., Leunissen, R. W. Breukhoven, P. E. \& Hokken-Koelega, A. C. Health profile of young adults born preterm: negative effects of rapid weight gain in early life. J. Clin. Endocrinol. Metab. 97, 4498-4506 (2012)

172. Breij, L. M., Kerkhof, G. F. \& Hokken-Koelega, A. C. Risk for nonalcoholic fatty liver disease in young adults born preterm. Horm. Res. Paediatr. 84, 199-205 (2015).

173. Carel, J. C., Chatelain, P., Rochiccioli, P. \& Chaussain, J. L. Improvement in adult height after growth hormone treatment in adolescents with short stature born small for gestational age: results of a randomized controlled study. J. Clin. Endocrinol. Metab. 88, 1587-1593 (2003)

174. Van Pareren, Y. et al. Adult height after long-term, continuous growth hormone $(\mathrm{GH})$ treatment in short children born small for gestational age: results of a randomized, double-blind, dose-response $\mathrm{GH}$ trial. J. Clin. Endocrinol. Metab. 88, 3584-3590 (2003).

175. Dahlgren, J., Wikland, K. A., \& Swedish Study Group for Growth Hormone Treatment. Final height in short children born small for gestational age treated with growth hormone. Pediatr. Res. 57, 216-222 (2005)

176. de Zegher, F., Ong, K. K., Ibanez, L. \& Dunger, D. B. Growth hormone therapy in short children born small for gestational age. Horm. Res. 65 (Suppl. 3), 145-152 (2006)

177. Sas, T., Mulder, P. \& Hokken-Koelega, A. Body composition, blood pressure, and lipid metabolism before and during long-term growth hormone $(\mathrm{GH})$ treatment in children with short stature born small for gestational age either with or without $\mathrm{GH}$ deficiency. J. Clin. Endocrinol. Metab. 85, 3786-3792 (2000).

178. Van Pareren, Y. et al. Effect of discontinuation of growth hormone treatment on risk factors for cardiovascular disease in adolescents born small for gestational age. J. Clin. Endocrinol. Metab. 88, 347-353 (2003).

179. Knop, C., Wolters, B. Lass, N. Wunsch, R. 8 Reinehr, T. Carotid intima-media thickness in children treated with growth hormone. J. Pediatr. Endocrinol. Metab. 28, 985-991 (2015)

180. Richelsen, B. Action of growth hormone in adipose tissue Horm Res 48 (Suppl. 5), 105-110 (1997).

181. Mukherjee, A., Murray, R. D. \& Shalet, S. M. Impact of growth hormone status on body composition and the skeleton. Horm. Res. 62 (Suppl. 3), 35-41 (2004).

182. Willemsen, R. H., Willemsen, S. P. \& HokkenKoelega, A. C. Longitudinal changes in insulin sensitivity and body composition of small-forgestational-age adolescents after cessation of growth hormone treatment. J. Clin. Endocrinol. Metab. 93 , 3449-3454 (2008)

183. Bratusch-Marrain, P. R., Smith, D. \& DeFronzo, R. A The effect of growth hormone on glucose metabolism and insulin secretion in man. J. Clin. Endocrinol. Metab. 55, 973-982 (1982)

184. Heptulla, R. A. et al. Decreased insulin sensitivity and compensatory hyperinsulinemia after hormone treatment in children with short stature. J. Clin. Endocrinol. Metab. 82, 3234-3238 (1997).

185. Cutfield, W. S. et al. Incidence of diabetes mellitus and impaired glucose tolerance in children and adolescents receiving growth-hormone treatment. Lancet 355, 610-613 (2000)

186. Sas, T. et al. Carbohydrate metabolism during long-term growth hormone treatment in childre with short stature born small for gestational age Clin. Endocrinol. (Oxf.) 54, 243-251 (2001).

187. Cutfield, W. S. et al. Reduced insulin sensitivity during growth hormone therapy for short children born small for gestational age. J. Pediatr. 142, 113-116 (2003).

188. Chatelain, P. Crabbe, R. Saunders, H. \& von Holtey, M. Changes in insulin sensitivity and glucose metabolism during therapy with recombinant human growth hormone in short children born small for gestational age show a negative correlation with baseline measurements. J. Pediatr. Endocrinol. Metab. 21, 329-338 (2008).

189. Lem, A. J. et al. Adult height in children born SGA treated with growth hormone and gonadotropin releasing hormone analog: results of a randomized, dose-response GH trial. J. Clin. Endocrinol. Metab 97, 4096-4105 (2012)

190. Van Der Steen, M. et al. Metabolic health in short children born small for gestational age treated with growth hormone and gonadotropin-releasing hormone analog: results of a randomized, doseresponse trial. J. Clin. Endocrinol. Metab. 100, 3725-3734 (2015)

191. Black, R. E. et al. Maternal and child undernutrition and overweight in low-income and middle-income countries. Lancet 382, 427-451 (2013).

192. Ibanez, L., Lopez-Bermejo, A., Diaz, M., Marcos, M. V. $\&$ de Zegher, F. Metformin treatment for four years to reduce total and visceral fat in low birth weight girls with precocious pubarche. J. Clin. Endocrinol. Metab. 93, 1841-1845 (2008)

193. Ibanez, L., Lopez-Bermejo, A., Diaz, M., Marcos, M. V. \& de Zegher, F. Pubertal metformin therapy to reduce total, visceral, and hepatic adiposity. J. Pediatr. 156 98-102 e 1 (2010)

194. Diaz, M., Bassols, J., Lopez-Bermejo, A., de Zegher, F. \& Ibanez, L. Metformin treatment to reduce central adiposity after prenatal growth restraint: a placebo-controlled pilot study in prepubertal children. Pediatr. Diabetes 16, 538-545 (2015).

195. Han, J., Xu, J., Epstein, P. N. \& Liu, Y. Q. Long-term effect of maternal obesity on pancreatic $\beta$ cells of offspring: reduced $\beta$ cell adaptation to high glucose and high-fat diet challenges in adult female mouse offspring. Diabetologia 48, 1810-1818 (2005)

196. Cordero, P., Campion, J., Milagro, F. I. \& Martinez, J. A. Transcriptomic and epigenetic changes in early liver steatosis associated to obesity: effect of dietary methyl donor supplementation. Mol. Genet. Metab. 110, 388-395 (2013).

197. Wang, H., Storlien, L. H. \& Huang, X. F. Effects of dietary fat types on body fatness, leptin, and ARC leptin receptor, NPY, and AgRP mRNA expression. Am. J. Physiol. Endocrinol Metab. 282 E1352-E1359 (2002)

198. Harder, T., Bergmann, R., Kallischnigg, G. \& Plagemann, A. Duration of breastfeeding and risk of overweight: a meta-analysis. Am. J. Epidemiol. 162 397-403 (2005).

199. Mericq, V. et al. Maternally transmitted and food derived glycotoxins: a factor preconditioning the young to diabetes? Diabetes Care 33, 2232-2237 (2010).

200. Rolland-Cachera, M. F., Deheeger, M., Akrout, M. \& Bellisle, $F$. Influence of macronutrients on adiposity development: a follow up study of nutrition and growth from 10 months to 8 years of age. Int. J. Obes. Relat. Metab. Disord. 19, 573-578 (1995).

201. Koletzko, B. et al. Lower protein in infant formula is associated with lower weight up to age $2 \mathrm{y}$ : a randomized clinical trial. Am. J. Clin. Nutr. 89 1836-1845 (2009)

202. Socha, P. et al. Milk protein intake, the metabolic-endocrine response, and growth in infancy: data from a randomized clinical trial. Am. J. Clin. Nutr. 94, (Suppl. 6) 1776S-1784S (2011).
203. Kirchberg, F. F et al. Dietary protein intake affects amino acid and acylcarnitine metabolism in infants aged 6 months. J. Clin. Endocrinol. Metab. 100 149-158 (2015)

204. Singhal, A. et al. Nutrition in infancy and long-term risk of obesity: evidence from 2 randomized controlled trials. Am. J. Clin. Nutr. 92, 1133-1144 (2010).

205. O'Connor, D. L. et al. Growth and nutrient intakes of human milk-fed preterm infants provided with extra energy and nutrients after hospital discharge. Pediatrics 121, 766-776 (2008).

206. Koo, W. W. \& Hockman, E. M. Posthospital discharge feeding for preterm infants: effects of standard compared with enriched milk formula on growth, bone mass, and body composition. Am. J. Clin. Nutr. 84, 1357-1364 (2006).

207. Agostoni, C. et al. Enteral nutrient supply for preterm infants: commentary from the European Society of Paediatric Gastroenterology, Hepatology and Nutrition Committee on Nutrition. J. Pediatr. Gastroenterol. Nutr. 50, 85-91 (2010).

208. Singhal, A., Fewtrell, M., Cole, T. J. \& Lucas, A Low nutrient intake and early growth for later insulin resistance in adolescents born preterm. Lancet 361 1089-1097 (2003).

209. Pittaluga, E. et al. Benefits of supplemented preterm formulas on insulin sensitivity and body composition after discharge from the neonatal intensive care unit. J. Pediatr. 159, 926-932.e2 (2011).

210. Clandinin, M. T. et al. Intrauterine fatty acid accretion rates in human brain: implications for fatty acid requirements. Early Hum. Dev. 4, 121-129 (1980).

211. Jiao, J. et al. Effect of $\omega$-3 PUFA supplementation on cognitive function throughout the life span from infancy to old age: a systematic review and meta-analysis of randomized controlled trials. Am. J. Clin. Nutr. 100, 1422-1436 (2014).

212. Ruzickova, J. et al. $\omega$-3 PUFA of marine origin limit diet-induced obesity in mice by reducing cellularity of adipose tissue. Lipids 39, 1177-1185 (2004).

213. Jump, D. B. Dietary polyunsaturated fatty acids and regulation of gene transcription. Curr. Opin. Lipidol. 13, 155-164 (2002)

214. White, P. J. et al. Transgenic $\omega-3$ PUFA enrichment alters morphology and gene expression profile in adipose tissue of obese mice: potential role for protectins. Metabolism 64, 666-676 (2015).

215. Ailhaud, G., Guesnet, P. \& Cunnane, S. C. An emerging risk factor for obesity: does disequilibrium of polyunsaturated fatty acid metabolism contribute to excessive adipose tissue development? Br. J. Nutr. 100, 461-470 (2008)

216. Levy, J. R., Clore, J. N. \& Stevens, W. Dietary $\omega-3$ polyunsaturated fatty acids decrease hepatic triglycerides in Fischer 344 rats. Hepatology 39, 608-616 (2004).

217. Gould, J. F., Smithers, L. G. \& Makrides, M. The effect of maternal $\omega-3(\omega-3)$ LCPUFA supplementation during pregnancy on early childhood cognitive and visual development a systematic review and meta-analysis of randomized controlled trials. Am. J. Clin. Nutr. 97, 531-544 (2013).

218. Willemsen, R. H. et al. Long-term effects of growth hormone $(\mathrm{GH})$ treatment on body composition and bone mineral density in short children born small-for-gestational-age: six-year follow-up of a randomized controlled GH trial. Clin. Endocrinol. (Oxf.) 67, 485-492 (2007).

\section{Acknowledgements}

The authors' work is supported by grants from the Fondo Nacional de Desarrollo Científico y Tecnológico (FONDECYT 7000939, 2010049, 1020965, 1030610, 1090028 1110240 and 1160836). The authors are grateful to H. Pogg (Pontificia Universidad Catolica de Chile) for review and thoughtful comments on the manuscript.

\section{Author contributions}

V.M., A.M.-A., R.U., G.I., M.V.d.S. and A.H.-K. researched the data for the article. V.M., A.M.-A. and G.I. provided substantial contributions to discussions of the content V.M. A.M.A. R.U., M.V.d.S. and A.H.-K. contributed equally to writing the article. V.M., A.M.-A., G.I. and A.H.-K undertook review and or editing of the manuscript before submission.

Competing interests

The authors declare no competing interests. 